\title{
Development of the quick prediction method for the strength of ground improved by jet grouting
}

\author{
Junichi Yamanobe ${ }^{\text {i) }}$, Munehito Endo ${ }^{\text {ii) }}$ and Kazuhito Komiya ${ }^{\text {iii) }}$ \\ i) Engineer, Chemical Grouting Co., Ltd., 2-2-5 Toranomon, Minato-ku, Tokyo 105-0001, Japan. \\ ii) Lecturer, Department of Civil and Environmental Engineering, Chiba Institute of Technology, 2-17-1 Tsudanuma, Narashino, Chiba, \\ 275-8588, Japan. \\ iii) President, Professor, Chiba Institute of Technology, 2-17-1 Tsudanuma, Narashino, Chiba, 275-8588, Japan.
}

\begin{abstract}
The strength of cement-stabilised soil mixed using the jet grouting method is generally evaluated by the unconfined compressive strength of core samples after 28 days of curing. If the 28-day in situ strength of the soil-cement mixture does not meet the design criteria, disposal of the deficient mixtures and reworking of the soil improvement are required, that may affect the construction period and cost. If the 28-day in situ strength can be predicted after a few days of mixing work, additional jet grouting work can be effectively performed if necessary, thereby reducing the impact on the construction schedule. In this study, laboratory tests were performed to estimate the 28-day strength of soil-cement mixture specimens using accelerated curing at high temperature for a few days. The effects of accelerated curing and mixture conditions on the strength properties of the soil-cement mixture specimens were investigated and the results validated the applicability of the high-temperature accelerated curing method for the evaluation of the 28-day strength.
\end{abstract}

Keywords: accelerated curing, soil-cement mixture, unconfined compressive strength

\section{INTRODUCTION}

The strength of cement-stabilised soil improved using the jet grouting method is generally evaluated by the unconfined compressive strength of drilled core samples after 28 days of curing for quality control purposes. Therefore, it is quite difficult to verify the in situ strength of the soil-cement mixtures immediately after the jet grouting work. When the in situ strength of the soil-cement mixture is insufficient to meet the design requirements after 28 days of curing, disposal of the deficient mixtures and reworking of the soil improvement are required, which may affect the construction period and cost. If the 28-day strength of the soil-cement mixtures can be predicted a few days after mixing and placement, additional jet grouting work can be performed, if necessary, thereby reducing the impact on the construction schedule.

Several studies have been conducted to evaluate the soil-cement mixture strength predicted from the early-age strength of soil-cement mixture. Babasaki (1981) prepared soil-cement mixture specimens using clay under curing temperatures ranging from $10{ }^{\circ} \mathrm{C}$ to $50{ }^{\circ} \mathrm{C}$ and curing periods of $1,3,7$ and 28 days. He compared the strengths of these specimens with the 28-day strengths of standard-cured specimens at $20{ }^{\circ} \mathrm{C}$. Some other studies also used soil-cement mixture specimens mixed using several soil samples, such as sandy soil, organic silt, clay, Kanto loam and andosol and subsequently established empirical equations to predict the 28-day strength based on the strength relationship between the soil-cement mixture specimens cured at $55{ }^{\circ} \mathrm{C}$ for a few days and those cured at $20{ }^{\circ} \mathrm{C}$ for 28 days (Murayama and Ichikawa, 2003; Kiyota et al., 1999). Similarly, some previously published researchers employed soil-cement mixture specimens cured at $40{ }^{\circ} \mathrm{C}, 50{ }^{\circ} \mathrm{C}$ and $60{ }^{\circ} \mathrm{C}$ for $24 \mathrm{~h}$ to predict the 28-day strength (Yamada and Fukuda, 1995 \& 1996; Fukuda and Yamada, 1996).

Furthermore, other researchers have applied the maturity rule proposed by Rastrup (1954), which is based on the function of the curing parameters (time and temperature), to estimate the 28-day strength of soil-cement mixture specimens mixed using clay and sandy soil and cured between $30^{\circ} \mathrm{C}$ and $65^{\circ} \mathrm{C}$ for 24 to 72h (Nakama et al., $2000 \&$ 2003; Noda et al., 2006). In all these studies, soil-cement mixture specimens cured at temperatures below $65^{\circ} \mathrm{C}$ for 24 to $72 \mathrm{~h}$ were used to predict the 28-day strength. Conversely, Komiya et al. (2015) studied the effects of accelerated curing on the early-strength development of soil-cement mixture specimens cured at temperatures above $70{ }^{\circ} \mathrm{C}$.

The main purpose of this study is to estimate the 28-day strength of cement-stabilised soils shortly after mixed by the jet grouting method. Soil-cement mixture 
specimens were sampled immediately after mixing and accelerated curing at high temperature. Laboratory tests were conducted to investigate the effects of accelerated curing parameters (temperature and time), fines content (FC) in the soils, cement content and water content of the soil-cement mixture specimens on their strength properties. Soil-cement mixture specimens were prepared using soil samples with different FC and were cured at temperatures above $70{ }^{\circ} \mathrm{C}$. Based on the results obtained from unconfined compression tests, the applicability of this estimation method was evaluated for actual construction work.

\section{SOIL PROPERTIES OF SAMPLES USED IN THE EXPERIMENTAL STUDY}

In this study, three kinds of soil samples with different FCs were prepared. The modification of the FC in each soil sample was executed by mixing Toyoura sand, Hakudo and clay mineral fine powder. These soil materials were commercially available. The grain-size distribution of each soil material is shown in Fig. 1, and the particle density and Atterberg limits for each soil material are presented in Table 1. Clay mineral fine powder, Hakudo and Toyoura sand were mixed in the following proportions by weight: $0: 15: 85$, 18:27:55 and 38:52:10. The FC of soil samples with these mix proportions were $17 \%, 44 \%$ and $83 \%$ (hereafter, FC17 soil, FC44 soil and FC83 soil, respectively). Figure 2 shows the grain-size distribution of these three soil samples.

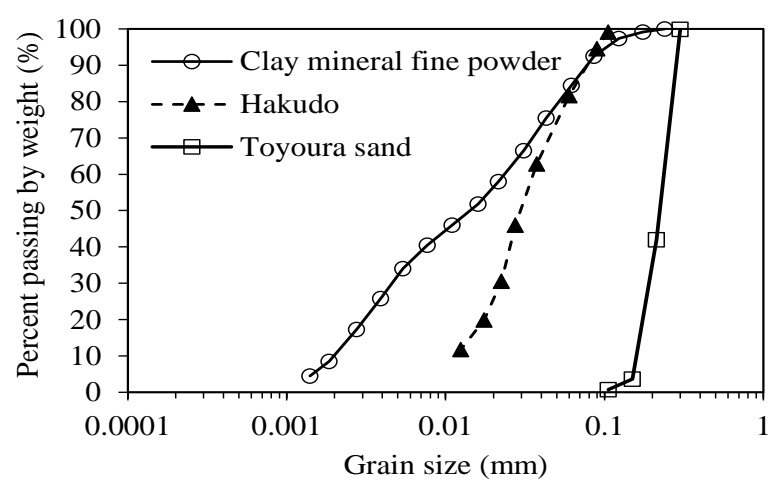

Fig. 1. Grain size distribution of soil materials.

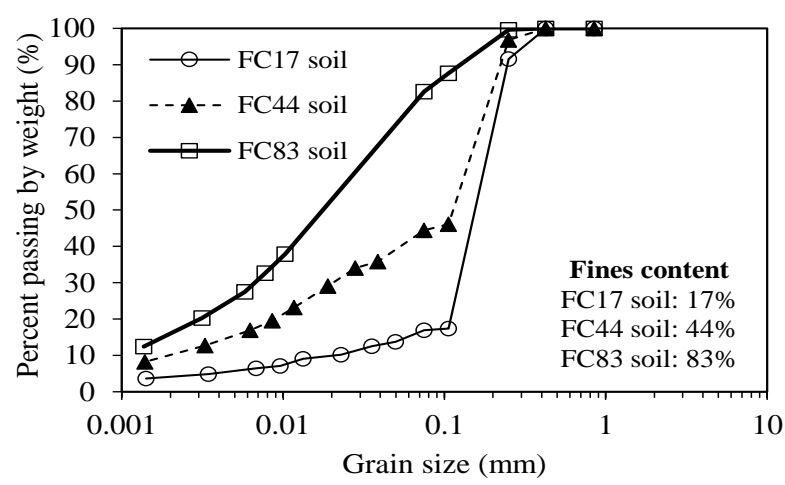

Fig. 2. Grain size distribution of soil samples.

\section{METHODS}

\subsection{Preparation for soil-cement mixtures and specimens}

In the laboratory experiments, each soil sample (FC17 soil, FC44 soil and FC83 soil) was mixed with cement based on the mixing proportions given in Table 2 to prepare the soil-cement mixture specimens for the unconfined compression test. The cement used in this study was a specialised cement used in the jet grouting method. Cement contents (C) of 100，150，200，250, 300,350 and $400 \mathrm{~kg} / \mathrm{m}^{3}$ with a water-cement ratio (W/C) of $100 \%$ were considered. The ratio of cement to water in the soil-cement slurry, $\left(\mathrm{C} / \mathrm{W}_{\mathrm{T}}\right)$, is also included in Table 2.

Table 1. Physical property of soil materials.

\begin{tabular}{|lr|c|c|c|}
\hline & $\begin{array}{c}\text { Clay mineral } \\
\text { fine powder }\end{array}$ & Hakudo & $\begin{array}{c}\text { Toyoura } \\
\text { sand }\end{array}$ \\
\hline \multicolumn{2}{|l|}{ Soil particle density } & $2.71 \mathrm{~g} / \mathrm{cm}^{3}$ & $2.43 \mathrm{~g} / \mathrm{cm}^{3}$ & $2.67 \mathrm{~g} / \mathrm{cm}^{3}$ \\
\hline Liquid limit & WL $_{\mathrm{L}}$ & 33.2 & 51.3 & \\
\hline Plastic limit & WP & 11.9 & 35.9 & \\
\hline Plasticity index & IP & 21.3 & 15.4
\end{tabular}

Table 2. Mix proportion of soil-cement mixture specimen.

\begin{tabular}{|c|c|c|c|c|c|c|c|}
\hline \multirow[b]{2}{*}{ Soil } & \multirow[b]{2}{*}{$\begin{array}{c}\mathrm{C} / \mathrm{W}_{\mathrm{T}} \\
(\%)\end{array}$} & \multicolumn{2}{|c|}{$\begin{array}{c}\text { Cement slurry } \\
\left(\mathrm{kg} / \mathrm{m}^{3}\right)\end{array}$} & \multicolumn{4}{|c|}{$\begin{array}{l}\text { Soil material } \\
\qquad\left(\mathrm{kg} / \mathrm{m}^{3}\right)\end{array}$} \\
\hline & & $\mathrm{C}$ & Water & Water & $\begin{array}{c}\text { Toyoura } \\
\text { sand }\end{array}$ & Hakudo & $\begin{array}{c}\text { Clay } \\
\text { mineral } \\
\text { fine } \\
\text { powder }\end{array}$ \\
\hline \multirow{7}{*}{$\begin{array}{l}\text { FC } \\
17\end{array}$} & 74 & 400 & 400 & 141 & 598 & 105 & 0 \\
\hline & 69 & 350 & 350 & 161 & 683 & 120 & 0 \\
\hline & 62 & 300 & 300 & 180 & 768 & 135 & 0 \\
\hline & 56 & 250 & 250 & 200 & 852 & 150 & 0 \\
\hline & 48 & 200 & 200 & 220 & 937 & 165 & 0 \\
\hline & 38 & 150 & 150 & 240 & 1022 & 180 & 0 \\
\hline & 28 & 100 & 100 & 260 & 1106 & 196 & 0 \\
\hline \multirow{7}{*}{$\begin{array}{r}\mathrm{FC} \\
44\end{array}$} & 65 & 400 & 400 & 214 & 295 & 145 & 96 \\
\hline & 59 & 350 & 350 & 245 & 337 & 165 & 110 \\
\hline & 52 & 300 & 300 & 275 & 378 & 186 & 124 \\
\hline & 45 & 250 & 250 & 305 & 420 & 206 & 137 \\
\hline & 37 & 200 & 200 & 336 & 462 & 227 & 151 \\
\hline & 29 & 150 & 150 & 366 & 504 & 248 & 164 \\
\hline & 20 & 100 & 100 & 396 & 545 & 267 & 177 \\
\hline \multirow{7}{*}{$\begin{array}{l}\mathrm{FC} \\
83\end{array}$} & 56 & 400 & 400 & 313 & 39 & 202 & 148 \\
\hline & 50 & 350 & 350 & 357 & 45 & 232 & 170 \\
\hline & 43 & 300 & 300 & 401 & 50 & 260 & 191 \\
\hline & 36 & 250 & 250 & 445 & 56 & 290 & 211 \\
\hline & 29 & 200 & 200 & 490 & 61 & 318 & 233 \\
\hline & 22 & 150 & 150 & 534 & 67 & 347 & 119 \\
\hline & 15 & 100 & 100 & 578 & 72 & 378 & 136 \\
\hline
\end{tabular}


The soil-cement mixture specimens were prepared in accordance with JGS 0821 (Japan Geotechnical Society, 2000). First, Toyoura sand, Hakudo, clay mineral fine powder and water were mixed using a cement mixer, according to the proportions listed in Table 2, and adjusted to the desired value of FC. After mixing, the soil samples were left to rest for an hour to enhance water absorption and eliminate entrapped air.

The soil-cement mixture was prepared by mixing the pre-mixed soil samples with the cement slurry for 10 min. Subsequently, the soil-cement mixture was cast in cylindrical moulds, that $5 \mathrm{~cm}$ in diameter and $10 \mathrm{~cm}$ in height. The height of the mould was increased by approximately $5 \mathrm{~cm}$ using duct tape around the top to prevent the loss of height due to bleeding. Soil-cement mixture specimens were subsequently left to rest for a few hours, following which the height of each soil-cement mixture specimen was adjusted to the top end of mould. All specimens were completely sealed using plastic film.

The soil-cement mixture specimens were subjected to either accelerated curing or standard curing. In the case of standard curing, the specimens were fully immersed in water at $20 \pm 3{ }^{\circ} \mathrm{C}$ for 28 days. In general, curing temperature is a factor that affects the unconfined compressive strength of soil-cement mixture (Japan Cement Association, 2014).

For accelerated curing, the effects of temperature and time on the strength of the soil-cement mixture specimens were examined. The curing temperatures considered were $40{ }^{\circ} \mathrm{C}, 50{ }^{\circ} \mathrm{C}, 60{ }^{\circ} \mathrm{C}, 70{ }^{\circ} \mathrm{C}, 80{ }^{\circ} \mathrm{C}, 90{ }^{\circ} \mathrm{C}$ and $100{ }^{\circ} \mathrm{C}$ for the curing times $10,24,48$ and $72 \mathrm{~h}$. In the accelerated curing experiments, an accelerated curing tank was used to prevent water evaporation due to the temperatures exceeding $70{ }^{\circ} \mathrm{C}$. A commercial pressure cooker was modified for the accelerated curing tank to maintain an internal pressure of $0.1 \mathrm{MPa}$ during curing. The soil-cement mixture specimens were placed inside the curing tank, and water was added just enough to cover the specimen surface. After securing the lid, the internal pressure inside the tank was raised to $0.1 \mathrm{MPa}$ using an air pump, and then the tank was stored in an oven under a fixed temperature and time period. The unconfined compression tests were conducted after the completion of the standard or accelerated curing processes.

\section{LABORATORY TEST RESULTS}

\subsection{Effects of curing temperature and time on the strength of soil-cement mixture specimens}

The unconfined compression tests were performed on the soil-cement mixture specimens mixed using FC17, FC44 and FC83 soil samples (hereafter, FC17 specimen, FC44 specimen and FC83 specimen, respectively), to investigate the effects of the curing temperature on the unconfined compressive strength (hereafter, $q_{u}$ ). The cement contents considered were
$250(\mathrm{C} 250)$ and $400 \mathrm{~kg} / \mathrm{m}^{3}$ (C400) for each soil sample. The soil-cement mixture specimens were cured at temperatures ranging from $40{ }^{\circ} \mathrm{C}$ to $100{ }^{\circ} \mathrm{C}$, in increments of $10{ }^{\circ} \mathrm{C}$ to $20{ }^{\circ} \mathrm{C}$, for $24 \mathrm{~h}$. Figures 3 (a)-(c) show the relationship between the $q_{u}$ and curing temperature for the FC17, FC44 and FC83 specimens, respectively. The solid and dashed lines show the $q_{u}$ (average values of four to eight specimens) for the C250 and C400 cement contents, respectively.

For soil-cement mixture specimens containing $\mathrm{C} 400, q_{u}$ appeared to gradually increase from $40{ }^{\circ} \mathrm{C}$ to $80{ }^{\circ} \mathrm{C}$ and became constant from $80{ }^{\circ} \mathrm{C}$ to $100{ }^{\circ} \mathrm{C}$. Conversely, in the case of the sample containing C250, the $q_{u}$ increased from $40{ }^{\circ} \mathrm{C}$ to $50{ }^{\circ} \mathrm{C}$ and then became

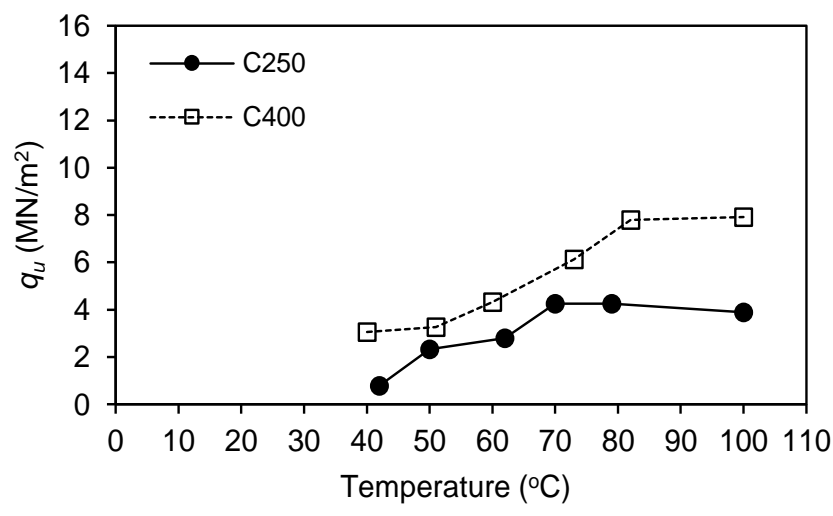

(a) FC17 specimen

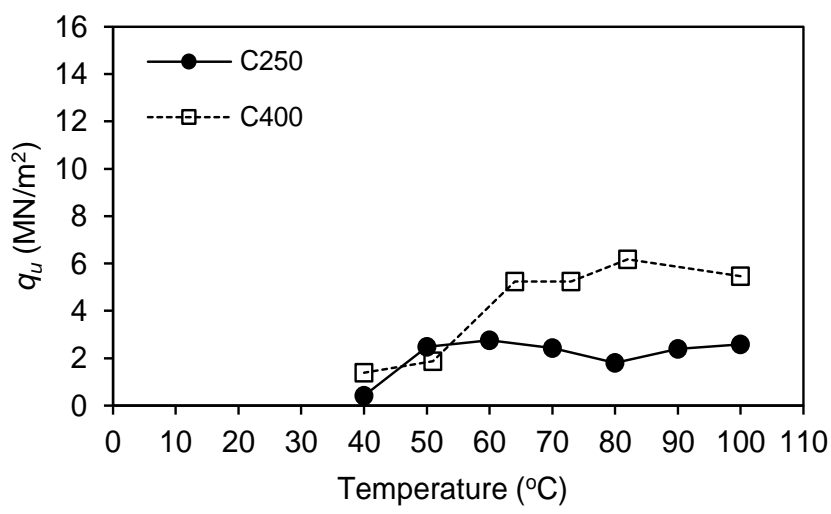

(b) FC44 specimen

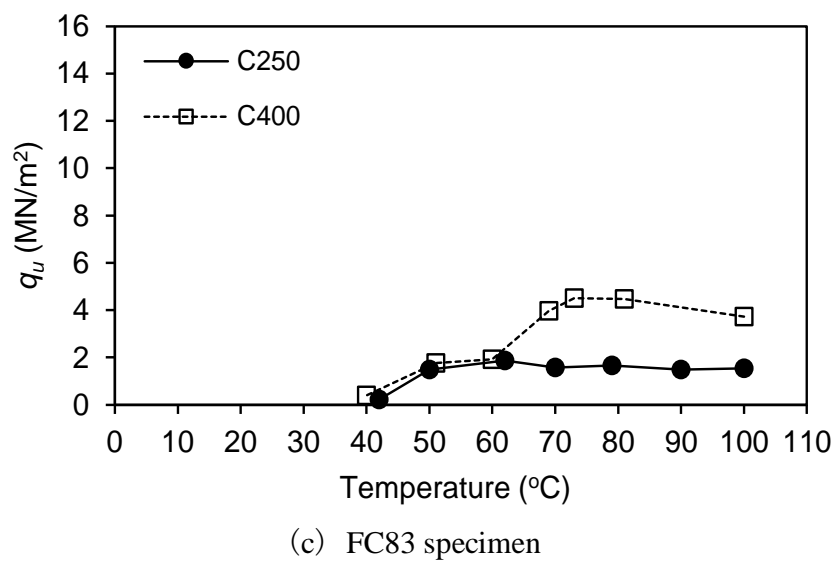

Fig. 3. Relationship between $q_{u}$ and curing temperature for $24 \mathrm{~h}$-cured soil-cement mixture specimens. 
constant from $50{ }^{\circ} \mathrm{C}$ to $100{ }^{\circ} \mathrm{C}$, with the exception of the FC17 specimen where the $q_{u}$ was fixed above $70{ }^{\circ} \mathrm{C}$. There appeared to be a range of temperature following which the $q_{u}$ remained constant for each tested case. Furthermore, specimens with larger cement contents appeared to achieve the same strength values under higher temperature as those with smaller cement contents.

Overall, the $q_{u}$ obtained from the soil-cement mixture specimens which underwent accelerated curing approximately ranged from 2 to $8 \mathrm{MN} / \mathrm{m}^{2}$. It was recognised that strengths tend to be consistent at higher temperatures between $80{ }^{\circ} \mathrm{C}$ and $100{ }^{\circ} \mathrm{C}$ for all tested cases. In general, the in situ strength of the

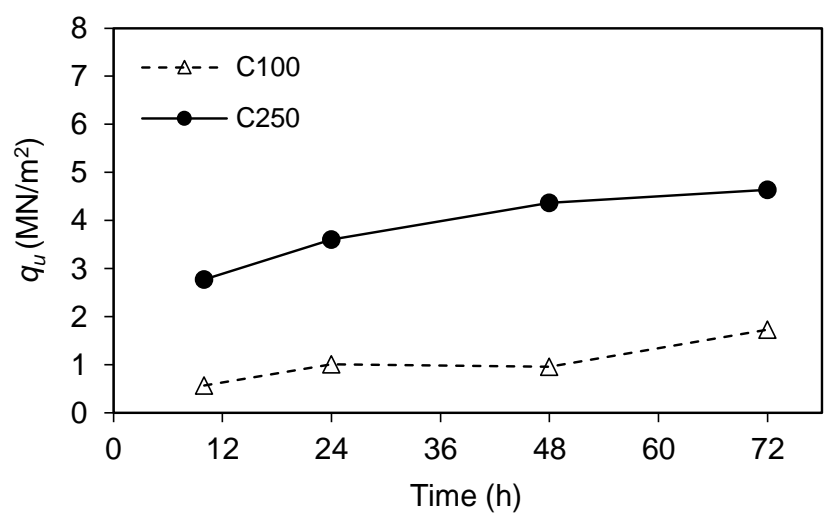

(a) FC17 specimen

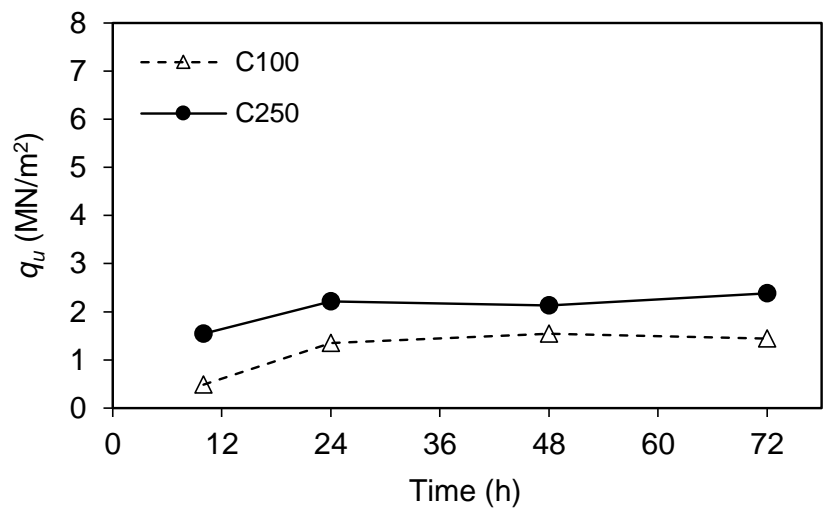

(b) FC44 specimen

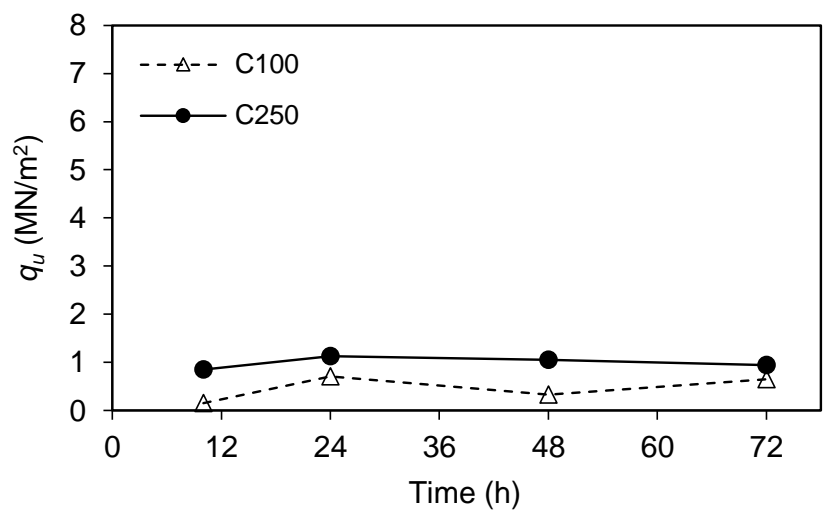

(c) FC83 specimen

Fig. 4. Relationship between $q_{u}$ and curing time for soil-cement mixture specimens cured at $100{ }^{\circ} \mathrm{C}$. cement-stabilised soil required for the jet grouting method ranges between 1 and $10 \mathrm{MN} / \mathrm{m}^{2}$. Thus, accelerated curing can be performed if a portable oven is available at the construction site.

Next, the effect of curing time on the $q_{u}$ was investigated for the FC17, FC44 and FC83 specimens. The cement contents considered were 100 (C100) and $250 \mathrm{~kg} / \mathrm{m}^{3}$ (C250) for each soil sample. The soilcement mixture specimens were cured at $100{ }^{\circ} \mathrm{C}$ for 10 , 24, 48 and $72 \mathrm{~h}$. Figures 4 (a)-(c) show the relationship between the $q_{u}$ and curing time for the FC17, FC44 and FC83 specimens, respectively. The solid and dashed lines represent the $q_{u}$ (average values of eight specimens) for the $\mathrm{C} 100$ and C250 cement contents, respectively. In the case of FC44 and FC83 specimens, the $q_{u}$ increased for $24 \mathrm{~h}$ and then became stable from 24 to $72 \mathrm{~h}$. By contrast, the $q_{u}$ gradually increased from 12 to $72 \mathrm{~h}$ for the case of the $\mathrm{FC} 17$ specimen.

Despite higher temperatures $\left(80{ }^{\circ} \mathrm{C}-100{ }^{\circ} \mathrm{C}\right)$, samples undergoing accelerated curing under fixed curing times achieved a stable strength value. It is clear that the accelerated cured strength can be reliably obtained with a curing time 24h. In the following tests, all soil-cement mixture specimens were cured for $24 \mathrm{~h}$ at $100{ }^{\circ} \mathrm{C}$.

\subsection{Effect of cement content on the strength of soil-cement mixture specimen subjected to accelerated curing at high temperature}

The effect of cement content on the $q_{u}$ was investigated for samples subjected to accelerated curing (FC17, FC44 and FC83 specimens) at high temperature. The cement contents considered were 100, 150, 200, $250,300,350$ and $400 \mathrm{~kg} / \mathrm{m}^{3}$. All specimens tested in this investigation were cured at $100{ }^{\circ} \mathrm{C}$ for $24 \mathrm{~h}$.

Figures 5 (a)-(c) show the relationship between the $q_{u}$ and cement content for the FC17, FC44 and FC83 specimens, respectively. The solid and dashed lines represent the $q_{u}$ (average values of four to eight specimens) for specimens subjected to accelerated and standard curing, respectively. Regardless of the FC of the soil samples, the $q_{u}$ increased relatively linearly with the increase in cement content, regardless of the type of curing. FC17 specimens possessing low FCs exhibited larger strength values, while the FC44 and FC83 specimens exhibited lower strength values. Overall, the $q_{u}$ tended to be lower with higher FC, elucidating that the strengths of the cement-stabilised soils were influenced by the FC (Japan Cement Association, 2014).

Figure 6 shows the relationship between the strength ratio and cement content. The strength ratio is defined as the ratio of $q_{u}$ of specimens subjected to accelerated curing to the $q_{u}$ of specimens subjected to standard curing. In the figure, the strength ratios for the FC17, FC44 and FC83 specimens are plotted as a function of the cement content. Typically the cement content frequently used in in situ soil improvement work ranges 
between 150 and $350 \mathrm{~kg} / \mathrm{m}^{3}$. In this range, the average strength ratios ranged from 0.3 to 0.7 with minor variation regardless of the $\mathrm{FC}$ of the soil samples and the cement content.

\subsection{Effect of water content on the strength of soil-cement mixture specimens subjected to accelerated curing at high temperature}

Soil moisture (water content) generally affects the strength of cement-stabilised soil (Japan Cement Association, 2014; Tang et al., 1999). The water content in the soil-cement mixture $\mathrm{W}_{\mathrm{T}}$, is defined as the sum of the water content in the soil sample and cement slurry. It is necessary to examine the effect of water in the soil-cement mixture on the strength characteristics.

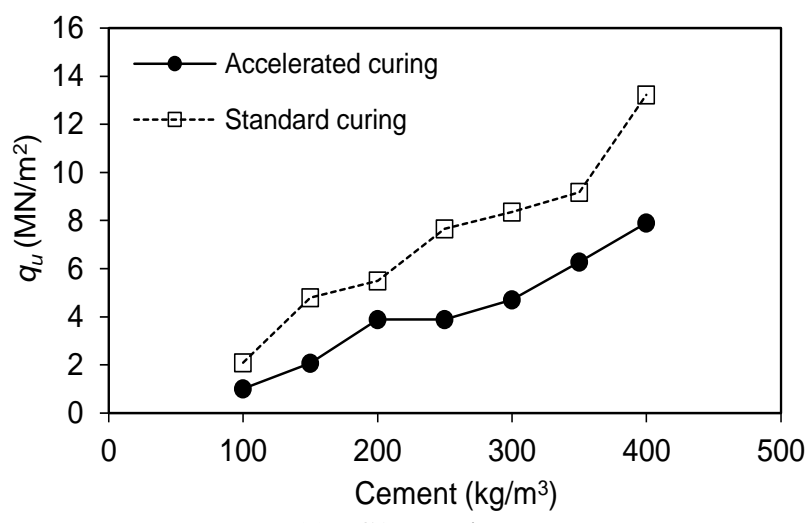

(a) FC17 specimen

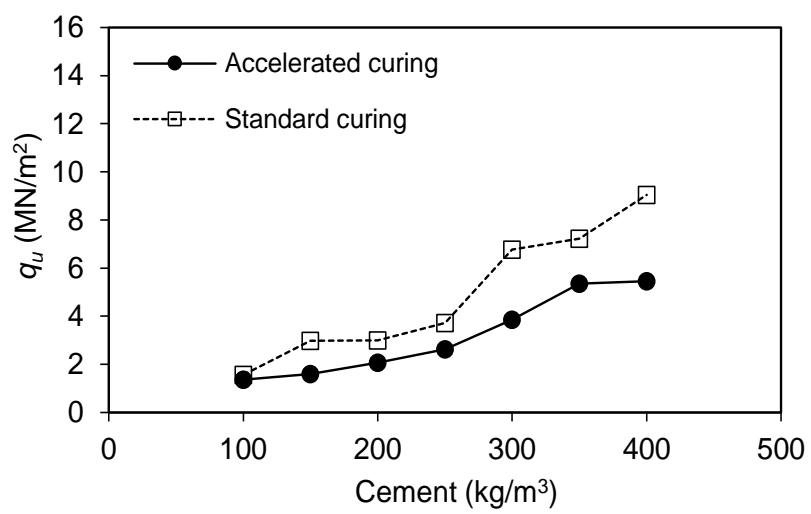

(b) FC44 specimen

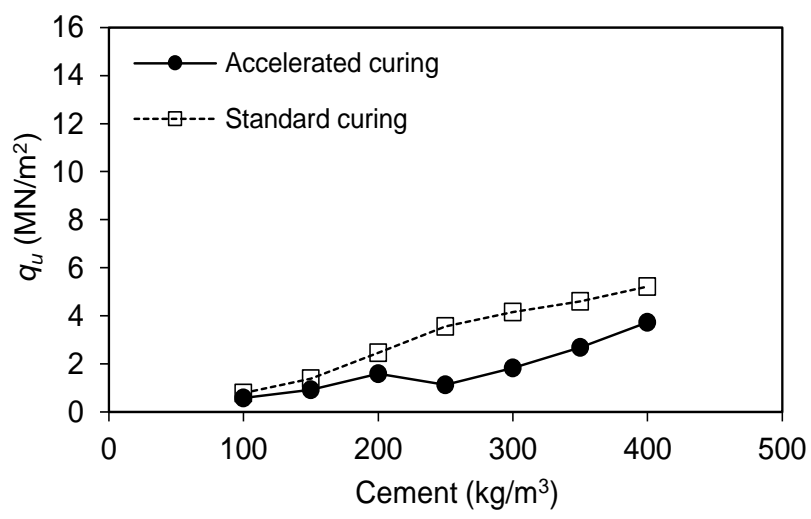

(c) FC83 specimen

Fig. 5. Relationship between $q_{u}$ and cement content for soil-cement mixture specimens.
Figure 7 shows the relationship between the $q_{u}$ and the ratio of cement to the $\mathrm{W}_{\mathrm{T}}, \mathrm{C} / \mathrm{W}_{\mathrm{T}}$, for the $\mathrm{FC} 17$, FC44 and FC83 specimens for accelerated and standard curing method. Overall, the $q_{u}$ linearly increased with increase in $\mathrm{C} / \mathrm{W}_{\mathrm{T}}$ for both accelerated and standard curing specimens, as observed in Fig. 5. This trend was observed for the 28-day unconfined compressive strength and agrees with the findings reported by Kinjo et al. (2004). However, it is important to note that the same characteristics were observed for soil-cement mixture specimens subjected to accelerated curing at high temperature for $24 \mathrm{~h}$.

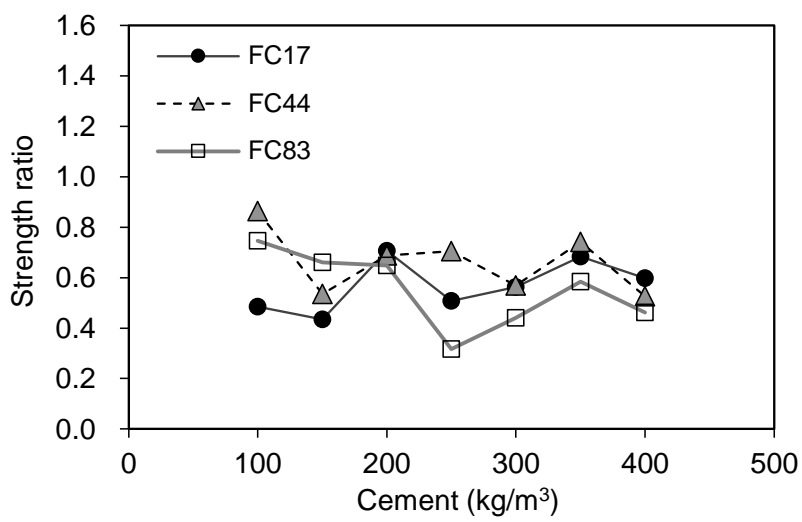

Fig. 6. Relationship between strength ratio and cement content for soil-cement mixture specimens.

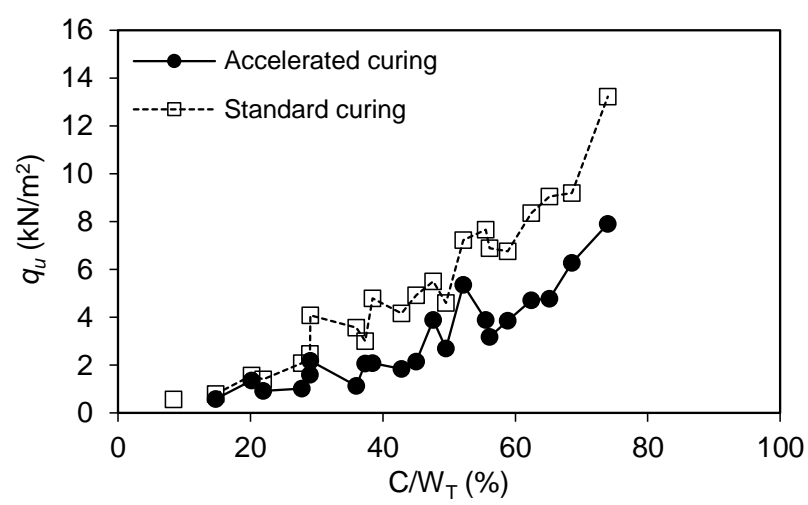

Fig. 7. Relationship between $q_{u}$ and $\mathrm{C} / \mathrm{W}_{\mathrm{T}}$ for all soil sample cases.

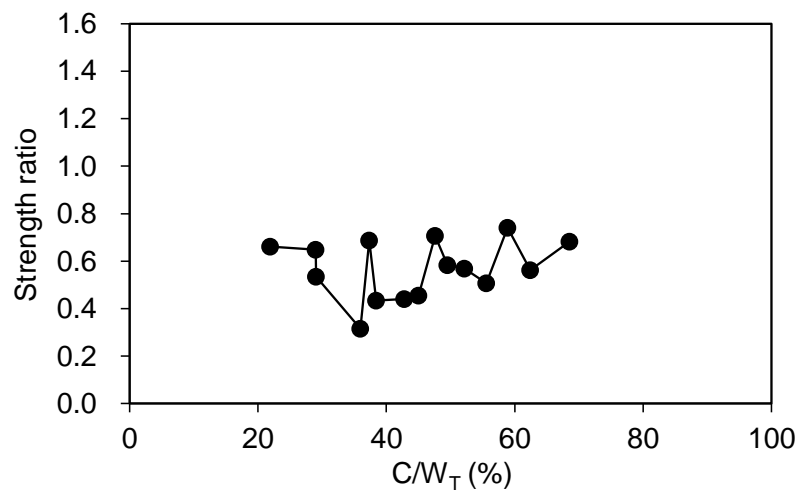

Fig. 8. Relationship between strength ratio and $\mathrm{C} / \mathrm{W}_{\mathrm{T}}$ for all soil sample cases. 
Figure 8 depicts the strength ratio as a function of $\mathrm{C} / \mathrm{W}_{\mathrm{T}}$. The cement contents considered ranged between $\mathrm{C} 150$ and C350. As can be seen in the figures, the average strength ratios approximately ranged between 0.3 and 0.7 for the $\mathrm{C} / \mathrm{W}_{\mathrm{T}}$ range between $20 \%$ and $70 \%$, which is the same trend shown in Fig. 6.

In this study, we validated that soil-cement mixture specimens subjected to high-temperature accelerated curing for $24 \mathrm{~h}$ can gain 0.3 to 0.7 times the strength of 28-day standard-cured specimens. Hence, it is suggested that prediction of the in situ strength of cement-stabilised soil using the high-temperature accelerated curing method can be used in actual construction work. However, in the case of a strength ratio exceeding 1 , the strength of specimens subjected to accelerated curing was higher than the 28-day cured strength. In this case, the in situ strength (28-day strength) of the cement-stabilised soil should not be predicted utilising the strength obtained by accelerated curing method because of the risk of underestimating the in situ strength.

\section{CONCLUSIONS}

In this study, laboratory tests were conducted to verify the applicability of a high-temperature accelerated curing method to estimate the 28-day unconfined compressive strength of cement-stabilised soils shortly after mixing work was performed using the jet grouting method. The effects of accelerated curing parameters (temperature and time), FC of soil, cement content and water content on the strength properties of the soil-cement mixture specimens subjected to accelerated curing at high temperatures were investigated.

The unconfined compressive strengths of the soil-cement mixture specimens subjected to accelerated curing became constant at higher temperatures between $80{ }^{\circ} \mathrm{C}$ and $100{ }^{\circ} \mathrm{C}$ and for curing time between 24 and $72 \mathrm{~h}$ regardless of the FC of the soil samples and the cement content. To investigate the effects of cement content and $\mathrm{C} / \mathrm{W}_{\mathrm{T}}$, all the soil-cement mixture specimens subjected to accelerated curing were cured at $100{ }^{\circ} \mathrm{C}$ for $24 \mathrm{~h}$. The strength linearly increased with an increase in cement content and $\mathrm{C} / \mathrm{W}_{\mathrm{T}}$ for both specimens subjected to accelerated curing and standard curing methods. Comparing the obtained strength ratio with practical ranges of cement content and $\mathrm{C} / \mathrm{W}_{\mathrm{T}}$, soil-cement mixture specimens subjected to high-temperature accelerated curing for $24 \mathrm{~h}$ can possibly gain 0.3-0.7 times of 28-day standard-cured strength. Therefore, the prediction of the in situ strength for cement-stabilised soil using the high-temperature accelerated curing method can be used in actual construction work.

\section{REFERENCES}

1) Babasaki, R., Kawasaki, T., Saito, S. and Inoue, T. (1981): Studies on deep mixing method using cement hardening agent (No.16) Influences of curing temperature on unconfined compressive strength of improved soils, Proc. 16th Japan National Conference on Geotechnical Engineering, 1725-1728 (in Japanese).

2) Fukuda, A. and Yamada, T. (1996): Estimation of compressive strength of soilcement within one day in high temperature curing (factors affecting correlation equation), Proc. 51st Annual Meeting of the Japan Society of Civil Engineers, 454-455 (in Japanese).

3) Japan Cement Association (2014): Soil improvement manual for cement-based stabilizer (in Japanese).

4) Japanese Geotechnical Society (2000): Testing methods and their interpretation for geotechnical materials (in Japanese).

5) Kinjo, N., Sakamaki, K., Tasaka, Y. and Takakura, A. (2004): Principle and application for solidifying soils 3 Characteristics of improved soils, Soil mechanics and foundation engineering, Japanese Geotechnical Society, 59-66 (in Japanese).

6) Kiyota, M., Nakamura, T., Tsutsumi, T., Oota, K. (1999): Estimation of strength of cement treated soil in hot water curing at an early stage, Proc. 34th Japan National Conference on Geotechnical Engineering, 851-852 (in Japanese).

7) Komiya, K., Yamanobe, J., Endo, M., Shiozawa, T. (2015): Accelerated curing and strength of soil-cement mixtures, Japanese Geotechnical Society Special Publication, 1(5), $12-16$

8) Murayama, A. and Ichikawa, S. (2003): The method of quality control of improvement ground, at an early stage, Proc. Annual Meeting of Architectural Institute of Japan, Tokai Chapter, Japan, 437-438 (in Japanese).

9) Nakama, T., Nakano, T., Saitoh, S. and Babasaki, R. (2000): Early stage estimation for strength of cement-improved soils, Proc. 55th Annual Meeting of the Japan Society of Civil Engineers, III-B214, 426-427 (in Japanese).

10) Nakama, T., Saitoh, S. and Babasaki, R. (2003): Early stage estimation for 28-day unconfined compressive strength of cement-improved soils using an accelerated curing test, Proc. 38th Japan National Conference on Geotechnical Engineering, 797-798 (in Japanese).

11) Noda, K., Saitou, S., Okumura R. and Kamao, S. (2006): Early stage prediction of 28 days unconfined compressive strength of cement-improved soil by accelerated curing, Proc. 41th Japan National Conference on Geotechnical Engineering, 765-766 (in Japanese).

12) Rastrup, E. (1954): Heat of hydration in concrete. Magazine of Concrete Research, 6(17), 79-92.

13) Tang, Y. X., Fujimura, H. and Tsuchida, T. (1999): A correlation among unconfined compression strength, cement content and water content for cement treated soils, Proceedings of 34th Japan National Conference on Geotechnical Engineering, 829-830 (in Japanese).

14) Yamada, T. and Fukuda, A. (1995): Estimation of compressive strength of soilcement within one day in high temperature curing, Proc. 30th Japan National Conference on Geotechnical Engineering, 2197-2198 (in Japanese).

15) Yamada, T. and Fukuda, A. (1996): Estimation of compressive strength of soilcement within one day in high temperature curing (application for field), Proc. 31th Japan National Conference on Geotechnical Engineering, 167-168 (in Japanese). 